\title{
Self-regulation and self-efficacy as mediators of achievement goals and leisure time physical activity: a proposed model
}

\author{
Erturan G. ${ }^{1 \mathrm{ABCDE}}$, McBride R. ${ }^{2 \mathrm{ADE}}$, Agbuga B. ${ }^{1 \mathrm{DE}}$ \\ ${ }^{1}$ Faculty of Sport Sciences, Pamukkale University, Turkey \\ ${ }^{2}$ College of Education \& Human Development, Department of Health \& Kinesiology, Texas A\&M University, USA
}

Authors' Contribution: A - Study design; B - Data collection; C - Statistical analysis; D - Manuscript Preparation; E - Funds Collection.

\begin{abstract}
Purpose:

The purpose of this study was to examine the mediating role of self-efficacy and self-regulation between achievement goals and leisure time physical activity among Turkish high school students.

Material:

Four hundred and sixty-four high school students ( 216 male; 248 female) enrolled in physical education classes voluntarily participated in the study. To assess whether the data fit the proposed model structural equation modelling was used.

Results: $\quad$ Results revealed that self-efficacy mediated the effects of mastery-approach, mastery-avoidance, and performance-approach goals on leisure time physical activity. Self-regulation was not a mediator of achievement goals and did not predict leisure time physical activity.

Conclusions: $\quad$ This study revealed the importance of self-efficacy in physical education to promote students' leisure time physical activity.

Keywords: $\quad 2 \times 2$ Achievement goal model, self-regulated learning, physical education, physical activity.
\end{abstract}

\section{Introduction}

Extensive data supports the importance of moderate to vigorous physical activity (MVPA) among children and youth. The (former) National Association for Sport and Physical Education (NASPE) concludes that regular PA is vital to preventing childhood obesity [1] and the World Health Organization (WHO) lists regular PA as an important goal for combating obesity and obesity-related diseases [2]. Despite compelling data, children and youth frequently fall below the recommended $\geq 50 \%$ level of MVPA [3, 4].

School physical education (PE) programs represent an important conduit for promoting PA. Given that long time outcome of $\mathrm{PE}$ is encouraging children and youth to engage in PA outside the gymnasium setting (i.e., during their leisure time), physical educators should understand factors contributing to PA outside of PE settings. Students must first want to engage in activity outside the school setting. Motivation represents an important contributor to promoting leisure time physical activity (LTPA). Appreciating students' motivations, cognitions and affects such as effort and self-efficacy may provide important knowledge and strategies for teachers to encourage PA in student leisure time. This study draws from self-regulation (SR) and achievement goal (AG) theoretical frameworks to examine the impact of high school students' AG, selfefficacy, effort and engagement in LTPA.

\section{Self-Regulation}

Perhaps one of the most inclusive theories aboutlearning is SR. While McBride \& Xiang [5] identified the lack of a consistent operational definition of SR in the literature, most agree it encompasses a process whereby individuals "activate and sustain cognitions, affects and behaviors that are systematically oriented toward the attainment of personal goals" [6; p.10]. SR individuals are active; they (c) Erturan G., McBride R., Agbuga B., 2020

doi:10.15561/18189172.2020.0102 manage learning through monitoring and strategy use. SR Theory embraces cognitive, metacognitive, motivational, behavioral strategies and social contextual factors where students actively and strategically oversee their learning [7]. It is driven by environmental setting circumstances that encourage individuals to "adopt, develop and refine strategies, monitor, evaluate, set goals, and change belief process" [8; p. 68].

SR also assumes that learners employ "agency" through active control and monitoring of their learning [9]. Working within the limits of personal capabilities as well as environmental influences, students exercise agency through goal setting, making decisions and choices about reaching those goals. Woven into the SR process is the intensity with which learners engage, persist, and believe in their abilities to accomplish tasks. Persistence, effort, and self-efficacy in fact, represent key affective indicators of SR [10] and are directly influenced by the extent to which learners might be internally or externally regulated. In the PE environment, Theodosiou and Papaioannou [11] found evidence that metacognitive elements of SR mediated the effects of a mastery climate and task orientation in PE classes on the frequency of exercise recorded in out-of-class sport venues.

\section{Achievement Goal Theory}

As noted by Zimmerman [12], Kaplan, Lichtinger, \& Gorodetsky [13] motivation is a major linchpin of SR. Among contemporary motivational theories, AG Theory addresses the role of cognitive, affective, and behavioral responses in educational and work-related settings. It attempts to explain how individuals in achievement situations seek to demonstrate ability and understand perceptions for engaging in achievement-related behaviors [14-16]. These purposes, in turn, then influence how students approach, experience and perform [17].

Two categories of AG initially identified (i.e., the 
dichotomous model) were task and ego. A task-oriented individual is self-referenced and motivated to develop competence and ability through learning or task mastery. Ego oriented learners focus on demonstrating superiority and outperforming others or show avoidance to being judged incompetent. Mixed research findings about relationships between the two AG motivational patterns led to the 2 × 2 model with four categories: masteryapproach (MAp; "I want to learn as much as possible"), mastery-avoidance (MAv; "I worry that I may not learn all that I possibly could"), performance-approach (PAp; "It is important for me to do better than other students"), and performance-avoidance (PAv; "I just want to avoid doing poorly") [18]. It has since been extensively validated among American, European, Asian, [19, 20] and Turkish adolescents [21].

In the $2 \times 2$ model, a MAp goal-orientation is associated with deep processing of material and increased SR [22]. MAv goals are associated with fear of failure and generally apply to achievement situations where individuals worry about skills loss [23]. Performanceapproach goal-orientations encompass a need for achievement while simultaneously embracing a fear of failure and are affiliated with persistence and effort [22]. Finally, a PAv goal orientation is driven by a fear of failure and represents the least positive goal orientation. One factor linked to PAv orientations is perception of overly externally regulated environments [24].

Self-efficacy

Bandura [25] defined self-efficacy (SE) as "beliefs in one's capabilities to organize and execute the courses of action required to produce given attainments" [p. 3]. When determining self-efficacy individuals judge their skills and capacities, then convert those skills into actions. Selfefficacy addresses beliefs about perceived competence or beliefs when approaching and performing tasks. Learners with high perceived self-efficacy levels tend to be more willing to engage in challenging tasks, work harder and persevere longer than their less efficacious counterparts.

Wigfield et al. [10] present a profile of high selfefficacy that include setting ambitious goals, choosing challenging tasks, and being mindful of requisite strategies needed to complete thought-provoking activities. Early correlational studies found positive relationships between self-efficacy and SR [see 26 for a more in-depth review). Classroom results also reveal self-efficacy mediated the effects of AG on academic outcomes. Bong [27] identified strong support for subject specificity of self-efficacy and AG among 424 Korean middle and secondary school students. PAp goals and PAv goals recorded strong crosssubject associations, while mastery goals recorded the weakest relationships. They concluded that students with PAp or PAv goal orientations in one academic subject would likely pursue the same goal orientation in other subject areas.

In the PA setting, self-efficacy has repeatedly predicted both adoption and maintenance of PA [28]. Among a population of young healthy adults, Kwan and Bryan [29] reported those who responded more favorably to exercise had greater self-efficacy, and Dishman et al. [30] recommended self-efficacy as a mediator variable.

Gao, Lochbaum, and Podlog [31] tested the mediating effect of self-efficacy among middle school students on targeted mastery AG and students' in-class PA. Students' self-efficacy was significantly and positively related to the four $A G$ and perceived motivation climates in addition to PA levels in PE class. Similarly, Gao and colleagues [32] provided additional support for self-efficacy as a mediator finding that middle school students' self-efficacy fully mediated the effect of MAp goals on a fitness performance and partially mediated the effects of MAv and PAp goals.

\section{Leisure Time Physical Activity}

Since adolescence may be a pivotal time for decisions about continued PA engagement, promoting LTPA takes on added importance. Aarnio, Winter, Peltonen, Kujala, $\&$ Kaprio [33] reported adolescents who actively engaged in PA were more likely to continue being physically active into adulthood. While research exploring the association of participation in PE and LTPA are mixed, one congruent link identified is the type of motivation students encounter [34]. Mastery-oriented and autonomy-supporting climates tend to foster greater intrinsic interest and future intentions to be physically active $[35,36]$.

In summary, $\mathrm{SR}, \mathrm{AG}$ orientations and self-efficacy represent important contributors to our understanding of learning and motivational behaviors in PE and PA settings. While empirical evidence provide links to self-efficacy, little information exists on the role self-efficacy and SR might play as mediators of AG and increased participation in LTPA. Cecchini-Estrada and Mendez-Gimenez [37] agree and provide support that $\mathrm{AG}$ orientations might yield implications for SR learning. Since PE is required in Turkey's high schools, SR and self-efficacy as mediators of LTPA could contribute to future interests in PA and health benefits accrued from such participation.

This study utilizes both SR and self-efficacy as mediators of AG and LTPA. Following the recommendation of Dishman et al. [30] and the impact of Gao and colleagues [32], we examine the mediating role of self-efficacy and SR between the 2 × 2 AG framework and LTPA among Turkish high school students. Specifically, this study asks: 1) Does the hypothesized model fit the data? 2) Do self-efficacy and SR mediate the effects of MAp, MAv \& PAp and LTPA and, 3) Do SR and selfefficacy predict LTPA?

Figure 1 presents the hypothesized model. Based on the previous studies we first hypothesized that approachoriented goals (MAp and PAp) would positively predict self-efficacy, while avoidance-oriented achievement goals (MAv and PAv) would negatively predict self-efficacy [e.g. 38]. Second, we hypothesized students' self-efficacy and SR would positively predict LTPA. Third we hypothesized that self-efficacy and SR would mediate the relationship between AG and LTPA. In line with earlier research [39, 31] self-efficacy was hypothesized to mediate $A G$ and LTPA. When experiencing success students may be more inclined to continue in that achievement behavior [40]. 


\section{Material and Method}

Participants.

Four hundred and sixty-four high school students (216 male; 248 female; age range $=14-17$ years, $(\mathrm{M}$ age $=15.04 \pm 0.62$ years) enrolled in PE classes voluntarily participated in the study. Participants attended five public high schools located in a central southwestern Turkish city and were of middle to upper middle-class SES. All programs delivered traditional sport-based lessons such as basketball, soccer, volleyball and games to meet state curriculum guidelines. Students typically participated for two hours one day per week and classes typically were teacher-centered. Distribution of gender and grade level are presented in Table 1.

Research Design

Prior to data collection permission was obtained from all participants and the Turkish Ministry of Education and Ethics Committee. During regularly scheduled PE classes, students responded to a questionnaire pack. Teachers were not present. Participants were informed there were no right or wrong answers, to respond as honestly as possible and participation in the research project (or not) would not impact their grade. Responses were kept confidential and took approximately 40 minutes to complete.

Variables and Measures

Questionnaires included demographic information and items assessing AG, SR, self-efficacy, and LTPA. Demographic information included name, age, gender, grade classification and course currently enrolled.
Achievement Goals. This construct was assessed using the $2 \times 2$ Achievement Goal Scale [41] and adapted to Turkish by Ağbuğa [21]. The questionnaire consists of 21 items beginning with the stem "in my physical education classes...." followed by a 7-point Likert scale $(1=$ not at all true of me; 7 = very true of

me). Item examples included "It is important for me to do better than other students" (PAp), "I just want to avoid doing poorly" (PAv), "I want to learn as much as possible" (MAp), and, "I worry that I may not learn all that I possibly could" (MAv).

Self-Regulation and Self-Efficacy. Related subscales from the Motivated Strategies for Learning Questionnaire [MSLQ; 42] was adapted for Turkish populations by Üredi [43] and confirmed by Erturan-İlker, Arslan and Demirhan [44] assessed students' SR and self-efficacy. The SR subscale consists of 9 items and the self-efficacy subscale consists of nine items. All items are followed by a 7-point Likert type scale $(1=$ not at all true of me; $7=$ very true of me). Example items included "When work is hard I either give up or study only the easy parts" (SR) and "Compared with other students in this class I expect to do well" (self-efficacy).

Leisure Time Physical Activity (LTPA). We used the adapted Turkish short form [45] of the International Physical Activity Questionnaire [IPAQ; 46]. It consists of 7 items that measure frequency, duration, and intensity of PA across the preceding seven days.

Statistical Analysis

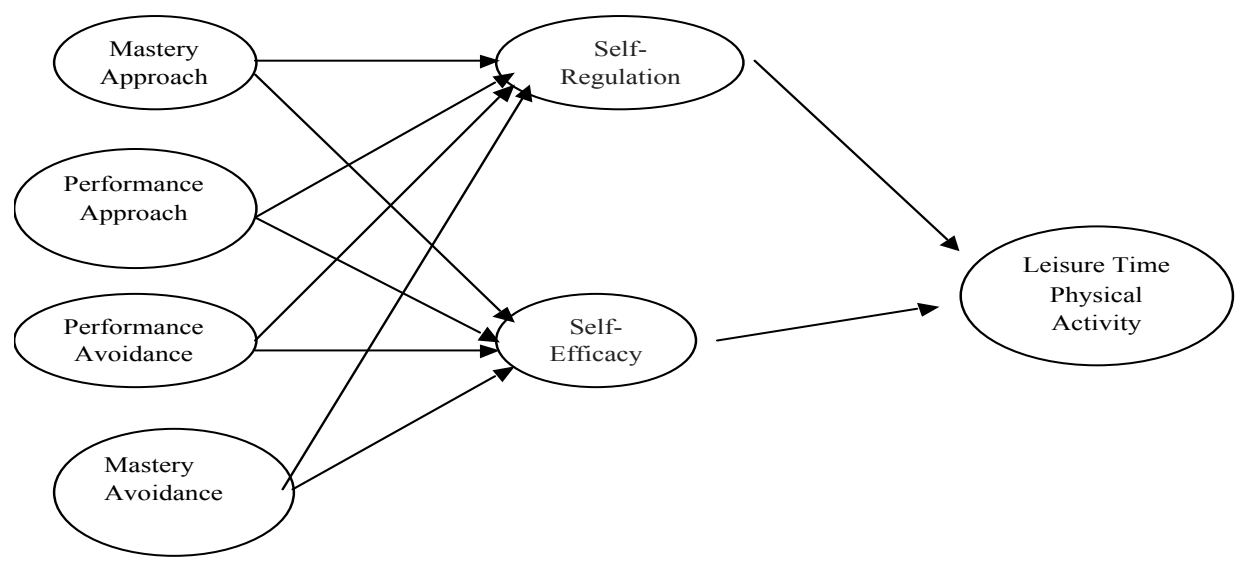

Figure 1. Hypothesized path model

Table 1. Distribution of participants by gender and grade level

\begin{tabular}{llllll}
\hline & Grade Level & & & & \\
\hline & 1 & 2 & 3 & 4 & Total \\
Girls & 82 & 60 & 46 & 60 & 248 \\
Boys & 66 & 54 & 47 & 49 & 216 \\
Total & 148 & 114 & 93 & 109 & 464 \\
\hline
\end{tabular}


Descriptive statistics for all variables were computed and Cronbach's alphas assessed the internal reliability of the multi-item subscales. Z scores for IPAQ scores were calculated. Pearson correlation analysis examined the correlations among all the variables used in the study. To assess whether the data fit the proposed model path analysis with the version 21 of the AMOS software [47]. In each analysis, we initially evaluated the multivariate normality of the data using Mardia's multivariate kurtosis coefficient.

Several indices were used to assess model fit. The overall fit of the model to the data employed the chisquare test. The standardized root means square residual (SRMR) and the root mean square error of approximation (RMSEA) were used as indicators of absolute fit. Values less than .08 and .06 respectively advocate a model with a good fit good fit between the proposed model and the data [48]. Comparative fit index (CFI) was to be less than 90 to indicate adequate model [48].

\section{Results}

Preliminary Analyses

After initial data screening, three univariate outliers were removed from the dataset. Means, standard deviations, and alpha reliability coefficients for the variables are recorded in Table 2 . The observed alpha coefficients indicated that the scales used in the study demonstrated acceptable internal reliability (i.e., a $\geq$ 0.70), except for PA, PAv goal, and SR.

Correlations among Variables

Pearson's product moment correlation analysis results are shown in Table 3 below. Bivariate correlations suggest that all the significant relationships are positive.

\section{Path Analysis}

The hypothesized path model was examined using the maximum likelihood method. The data in the measurement model did not display multivariate normality (Mardia's Multivariate kurtosis $=12.94$ ). Multivariate normality implies that the sampling distributions of means of the

Table 2. Descriptive characteristics of participants

\begin{tabular}{lccccccc}
\hline Characteristics & N & M & SD & Range & Skewness & Kurtosis & $\boldsymbol{\alpha}$ \\
\hline $\begin{array}{l}\text { Physical Activity* } \\
\text { Mastery Avoidance }\end{array}$ & 306 & 2227.06 & 1976.11 & - & & 0.69 \\
Performance Avoidance & 306 & 4.00 & 1.57 & $1-7$ & -0.155 & -0.780 & 0.71 \\
Mastery Approach & 306 & 5.07 & 1.36 & $1-7$ & -0.771 & 0.271 & 0.62 \\
Performance Approach & 306 & 5.19 & 1.15 & $1-7$ & -0.733 & 0.235 & 0.78 \\
Self-Efficacy & 306 & 4.95 & 1.39 & $1-7$ & -0.733 & -0.010 & 0.84 \\
Self-Regulation & 306 & 5.30 & 1.18 & $1-7$ & -0.846 & 0.330 & 0.90 \\
\hline
\end{tabular}

*PA scores were calculated as MET/minute/week and were included as original IPAQ scores

Table 3. Bivariate correlations among study variables

\begin{tabular}{|c|c|c|c|c|c|c|}
\hline Variables & 1 & 2 & 3 & 4 & 5 & 6 \\
\hline 1. SR & - & & & & & \\
\hline 2. Self-Efficacy & 0.02 & - & & & & \\
\hline 3. PAp & 0.07 & $0.34 * *$ & - & & & \\
\hline 4. $M A p$ & $0.18^{* *}$ & $0.49 * *$ & $0.56 * *$ & - & & \\
\hline 5. PAv & -0.00 & $0.14 *$ & $0.25^{* *}$ & $0.012 *$ & - & \\
\hline 6. MAv & -0.04 & $0.17^{*}$ & $0.41 * *$ & $0.34 * *$ & $0.31 * *$ & - \\
\hline 7. LTPA & $0.13^{*}$ & $0.29 * *$ & $0.13^{*}$ & $0.29 * *$ & 0.06 & 0.010 \\
\hline
\end{tabular}

${ }^{*} p<0.05, * * p<0.01$ 
various dependent variables in each cell and all linear combinations of them are normally distributed [49]. One approach to handling multivariate non-normal data set is the bootstrap technique [50] that was employed in all further analyses and the calculation of model statistics, parameters, and standard errors are derived from the bootstrap sample distribution.

Because the AGs were interrelated their associated error terms were correlated, the indices of fit suggested the revised model adequately fit the data $\left[X^{2}(\mathrm{sd})=2.55, p\right.$ $<0.05, \mathrm{CFI}=0.98, \mathrm{NFI}=0.96, \mathrm{SRMR}=0.00, \mathrm{RMSEA}=$ 0.043]. See Figure 2.

According to the path model, MAv goals a revealed negative relationship with SR and self-efficacy, while the MAp goal revealed a positive relationship with SR and self-efficacy. The PAp goal showed only a positive association with self-efficacy. Lastly, the PAv goal produced no relationship with variables. Self-efficacy is an important variable in the model due to its direct link with LTPA. It positively predicted LTPA and was a mediator between AG and LTPA. Contrary to our hypotheses, SR did not significantly predict LTPA. The percentage of variance (squared multiple correlations) accounted for in each dependent variable were: Self-efficacy: $27 \%$, LTPA: $9 \%$, and SR: 5\%. All $R^{2}$ were statistically significant $(p<$ $.01)$.

\section{Discussion}

This study tested a hypothesized model examining the mediating role of self-efficacy and SR on the effects of the $2 \times 2$ AG model and LTPA among Turkish high school students. After initial lack of model fit, follow-up analysis techniques yielded an acceptable fit for the final model. Results revealed self-efficacy partially mediated the effects of three of the four AG on LTPA. SR was not a mediator of AG and did not predict LTPA. However, a MAp orientation revealed a positive relationship with SR while a MAv goal orientation produced a negative relationship with SR.

The first hypothesis stated that MAp, MAv, PAp and PAv would significantly predict self-efficacy and SR. The MAp coefficient was significantly and moderately related to self-efficacy, followed by PAp and MAv goal orientations. The MAv relationship with self-efficacy was statistically significant but negative in direction and recorded the smallest absolute value. These findings correspond to AG Theory where MAp and PAp positively associate with perceived competence, while MAv has a negative association with perceived incompetence [51]. Gao et al. [31] also confirmed this goal and suggested individuals endorsing MAp and PAp goals over MAv goals may expedite their own self-efficacy. Whether competence is perceived as mastery or task-oriented, the approach valence may be assumed to relate positively to self-efficacy. Teachers may benefit from these results through the creation of an 'approach-centered' climate that encourages and supports their student's efforts.

Only the mastery goals predicted SR. The obtained result adds further support that MAp and PAp goal orientations are positively linked to perceived competence and can operate simultaneously in the same environment, while MAv is negatively linked with perceived incompetence [52]. Since both goal orientations' positive valence (i.e., approach) yielded significant and positive predictions of self-efficacy, there are implications for practice. Though a general mastery orientation to learning is positively related to learning and self-motivation, some students respond to competition and assessing performance relative to others. Teachers might provide activities offering a blend of both approach orientations while still emphasizing task mastery and personal improvement.

That self-efficacy would mediate the effects of the four AG goals on SR and LTPA was partially met. Except for PAv, all were significant predictors of self-efficacy. MAv was not a significant predictor of self-efficacy. Specifically, the MAp coefficient was significantly related to self-

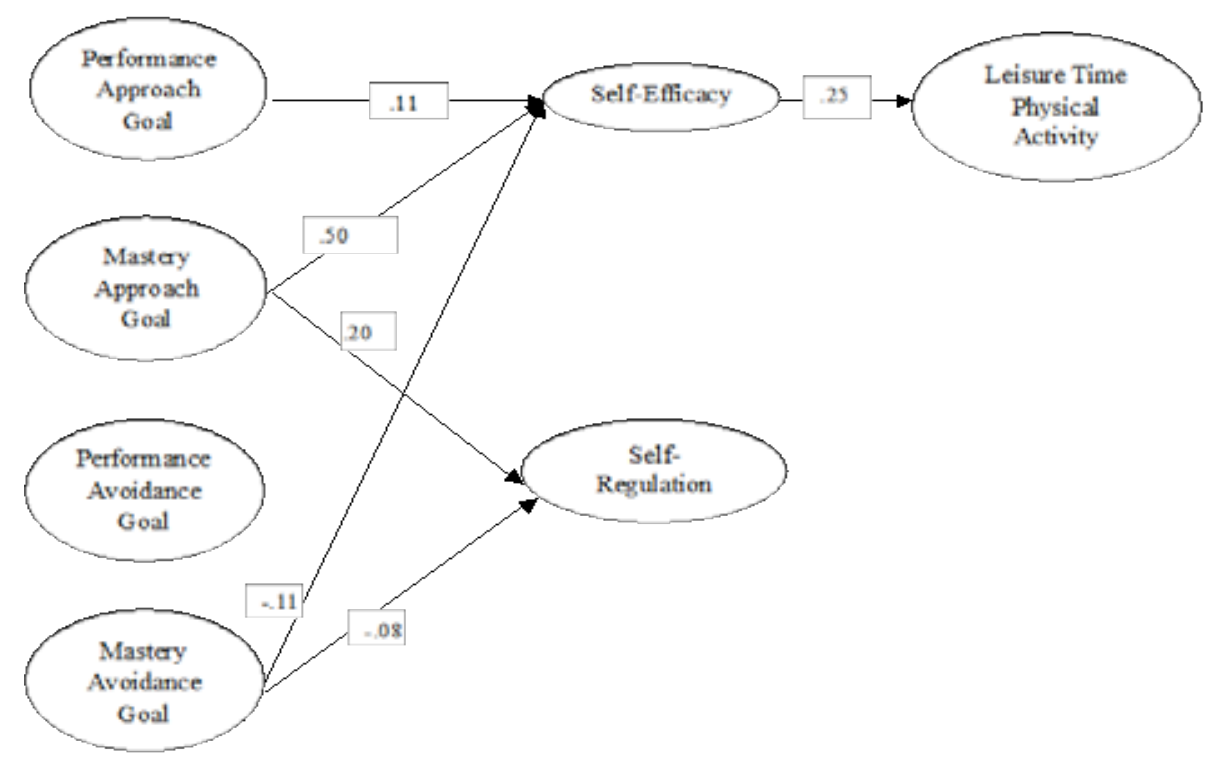

Figure 2. The path model of the interrelationships between LTPA, AG, SR and SE. Note. All coefficients presented are standardized and significant. For visual simplicity variances are not presented. 
efficacy, followed by PAp. The MAv relationship with self-efficacy was statistically significant, but negative in direction. The results add further support to the theoretical underpinning that both MAp and PAp goal orientations are positively related to perceived competence and MAv is negatively correlated with perceived incompetence [32, 52]. For PE practitioners, both mastery and performance approach goal orientations can operate simultaneously in a perceived mastery-involving climate where students believe they are capable of performing activity [31, 17].

Self-efficacy fully mediating the effects of PAp and MAv goals and partially mediating MAp and LTPA is supported by related research. Gao et al. [32] reported that students' self-efficacy fully mediated the effect of MAp on a fitness test and partially mediated the effects of MAv and PAp on the same fitness test. Using the dichotomous AG model, Li, Shen, Rukavina, and Sun [53] found that both mastery and performance goals positively predicted perceived competence among a sample of middle school students. The current results offer further documentation that students exhibiting an ego-involved goal orientation with an avoidance valance may not automatically display maladaptive behaviour in achievement settings [54]. That both high-task/low-ego and high-task/high ego configurations have been found to be motivationally adaptive bodes well for PE. Motivationally adaptive students work harder, record higher levels and selfefficacy and attribute success to their effort [55]. Teachers should be prepared for multiple goal orientations in their classes and include a variety of mastery and task-oriented activities.

Though the performance avoidance goal orientation revealednosignificantpaths, studentsneverthelessrecorded higher than average subscale scores $(M=5.07)$. According to AGT, a negative valence indicates behaviour initiated via deleterious or undesirable events or possibilities and are problematic in achievement situations [23]. Fear of failure is often an underlying motive for performanceavoidance learners. A performance-avoidance associated with surface processing of material, avoiding help seeking, and a perception that the achievement context is overly evaluative.

These characteristics are of potential concern because Wolters et al. [55] found that students reporting a high extrinsic goal focus tended to have lower levels of selfefficacy. As seen in the results, a MAv goal orientation negatively predicted self-efficacy. Physical educators, along with a mastery approach, might establish an environment that fosters student self-efficacy while simultaneously reducing external regulators that might enhance a performance avoidance goal orientation.

Contrary to the proposed model, SR was not a mediator of AG and LTPA and did not predict LTPA. One reason for the lack of mediation/predictability of SR may be due to the instrument. Research findings on reliability and factor validity of the MSLQ are mixed. While early research on the MSLQ found acceptable internal consistency reliability, confirmatory factor analysis demonstrated modest fits only [56]. Cook et al. [56] also produced results where Confirmatory Factor Analysis did not demonstrate a good fit but a follow-up Exploratory Factor Analysis suggested a five-factor model. Though adapted for and validated in a Turkish setting, the MSLQ is designed primarily for traditional achievement-oriented environments and may not have captured the context afforded in this setting.

High school PE in Turkey follows a traditional sportsoriented curriculum model delivered through teachercentered instruction. Under these conditions, students may not be exposed to SR opportunities and thus may not have associated the SR items with their PE classes and intentions for future LTPA. Like any skill set, SR skills must be taught and students provided with opportunities for application. Both an examination of the contextspecificity of the items and opportunities for SR in the environment may provide more definitive clues for the lack of predictability SR played here.

Finally, the model proposed that self-efficacy and SR would predict LTPA. That self-efficacy was positively related to LTPA supports previous research identifying efficacy as a predictor of PA. McAuley and Blissmer's [57] review of the predictive role of self-efficacy to exercise yielded powerful relationships. The authors reported that changes in self-efficacy over time directly related to changes in exercise behavior and predicting long-term adherence to PA. To foster belief about capabilities to engage in PA, teachers can provide students with a variety of co-operative and competitive activities as well as opportunities for success. Providing a selection of activities combined with successful engagement can enhance the likelihood of students continuing PA after their high school years.

There are, however, limitations to note. First is using self-report measures. Cross-sectional nature designs may not permit the testing of reciprocal links which may appear over time. Future research might employ a longitudinal design whereby serial measurements are made in the same individuals over time. Another limitation was the LTPA assessment. Since IPAQ requires respondents to recall PA over the past week, the reliability of the data depends on adolescents' memory. To overcome this limitation, future studies may use specific PA measures during leisure time to assess LTPA.

\section{Conclusion}

Despite these limitations the study contributes to a better understanding of the mediating role of self-efficacy in the relationships among the $2 \times 2 \mathrm{AG}$ orientations and LTPA by including SR as a mediator of LTPA. Though numerous studies include self-efficacy as a mediator among a variety of outcome variables, SR has largely been ignored. To the authors' knowledge, no study has included SR as a mediator AG to include and predict LTPA employing path analysis techniques.

Though SR did not mediate AG nor predict LTPA, there is a long-established relationship between goal orientations and SR. Since this relationship was not confirmed among these Turkish high school students, 
further study is recommended to assess why SR had little impact on LTPA and what environmental factors might account for the lack of predictability.

\section{Conflict of interests}

The authors state that there is no conflict of interest

\section{References}

1. National Association for Sport and Physical Education. Shape of the nation report: Status of PE in the USA. Reston, VA: American Alliance for Health, Physical Education, Recreation \& Dance; 2012.

2. World Health Organization. Global strategy on diet, physical activity and health. Geneva: world health organization. The Fifty-Seventh World Health Assembly; 2004

3. Pate R, O'Neill J, McIver K. Physical activity and health: Does physical education matter? Quest 2011; 63:19-35. https://doi.org/10.1080/00336297.2011.10483660

4. Wilkie H, Standage M, Sherar L, Cumming S, Parnell C, Davis A, Foster C, Jago R. Results from England's 2016 report card on physical activity for children and youth. Journal of Physical Activity and Health, 2016; 13: 143-149. https://doi.org/10.1123/jpah.2016-0298

5. McBride R, Xiang P. Self-regulated learning and perceived health among students participating in university physical activity classes. Journal of Teaching in Physical Education, 2013; 32:220-236. https://doi.org/10.1123/jtpe.32.3.220

6. Zimmerman B, Schunk D. Self-regulated learning and performance: An introduction and an overview. In: Zimmerman B, Schunk D, editors. Handbook of selfregulation of learning and performance New York: Routledge; 2011. P.1-12.

7. Pintrich PR. The Role of Goal Orientation in Self-Regulated Learning. Handbook of SelfRegulation, Elsevier; $2000 . \quad$ P.451-502. https://doi.org/10.1016/B978-012109890-2/50043-3

8. Hadwin A, Jarvela S, Miller M. Self-regulated, co-regulated and socially shared regulation. In: Zimmerman B; Schunk $\mathrm{D}$, editors. Handbook of self- regulation of learning and performance. New York, NY. Routledge; 2011. P. 65-84.

9. Winne P, Hadwin A. The weave of motivation and selfregulated learning. In: Schunk D, Zimmerman B, editors. Motivation and self-regulated learning adolescents with Asian, Latino, and European American backgrounds. Journal of Educational Psychology 2008; 99: 584-596.

10. Wigfield A, Klauda S, Cambria J. Influences on the development of academic self-regulatory processes. In: Zimmerman B, Schunk D, editors. Handbook of selfregulation of learning and performance, New York, NY. Routledge; 2011. P. 33-48.

11. Theodosiou A, Papaionannou A. Motivational climate, achievement goals and metacognitive activity in physical education and exercise involvement in out-of- school settings. Psychology of Sport and Exercise, 2006; 7: 361-379. https://doi.org/10.1016/j.psychsport.2005.10.002

12.Zimmerman B. Becoming a self-regulated learner: An overview. Theory into Practice, 2002; 41: 64-70. https://doi.org/10.1207/s15430421tip4102 2

13.Kaplan S, Lichtinger E, Gorodetsky M. Achievement goal orientations and self-regulation in writing: An integrative perspective. Journal of Educational Psychology, 2009; 10: 51-69. https://doi.org/10.1037/a0013200

14.AmesC.Classrooms: Goals, structures, and studentmotivation. Journal of Educational Psychology, 1992; 84: 261-272. https://doi.org/10.1037//0022-0663.84.3.261

15.Dweck C. Motivational processes affecting learning.
American Psychologist, 1986; 41: 1040-1048. https://doi.org/10.1037//0003-066X.41.10.1040

16.Nicholls J. The competitive ethos and democratic education. Cambridge: MA. Harvard University Press; 1989.

17.Xiang P, McBride R, Guan J. Children's motivation in elementary physical education: A longitudinal study. Research Quarterly for Exercise and Sport, 2004; 75: 71-80. https://doi.org/10.1080/02701367.2004.10609135

18. Elliot A, McGregor H. A 2 x 2 achievement goal framework. Journal of Personality and Social Psychology, 2001; 83: 501-519. https://doi.org/10.1037//0022-3514.80.3.501

19. Warburton V, Spray C. Antecedents of approachavoidance achievements goal adoption: An analysis of two physical education activities. European Physical Education Review, 2013; 19: 215-231. https://doi.org/10.1177/1356336X13486055

20.Witkow M, Fulgini A. Achievement goals and daily school experiences among adolescents with Asian, Latino, and European American backgrounds. Journal of Educational Psychology, 2007; 99: 584-596. https://doi.org/10.1037/0022-0663.99.3.584

21.Ağbuğa B. Reliability and validity of the trichotomous and $2 \times 2$ achievement goal models in Turkish university physical activity settings. Journal of Human Kinetics, 2009; 22: 77-82. https://doi.org/10.2478/v10078-009-0026-1

22. Wolters C. Advancing achievement goal theory: using goal structures and goal orientations to predict students' motivation, cognition, and achievement. Journal of Educational Psychology 2004; 96: 236-250. https://doi.org/10.1037/0022-0663.96.2.236

23.Fryer JW, Elliot AJ. Stability and change in achievement goals. Journal of Educational Psychology, 2007;99:700-14. https://doi.org/10.1037/0022-0663.99.4.700

24.Church M, Elliot A, Gable S. Perceptions of classroom environment, achievement goals and achievement outcomes. Journal of Educational Psychology, 2001; 93: 43-54. https://doi.org/10.1037//0022-0663.93.1.43

25.Bandura A. Editorial. American Journal of Health Promotion, 1997; 12(1): 8-10. https://doi.org/10.4278/0890-1171-12.1.8

26.Schunk D, Usher E. Assessing self-efficacy for self-regulated learning. In: Zimmerman B, Schunk D, editors. Handbook of self-regulation of learning and performance. New York, NY: Routledge; 2011. P. 282-297.

27.Bong M. Between-and within-domain relations of academic motivation among middle and high school students: Self-efficacy, task-value, and achievement goals. Journal of Educational Psychology, 2001; 93: 23-34. https://doi.org/10.1037//0022-0663.93.1.23

28.Strachan SM, Woodgate J, Brawley LR, Tse A. The relationship of self- efficacy and self-identity to longterm maintenance of vigorous physical activity. Journal of Applied Biobehavioral Research, 2005; 10: 98-112. https://doi.org/10.1111/j.1751-9861.2005.tb00006.x

29.Kwan B, Bryan A. Affective response to exercise as a component of exercise motivation: Attitudes, norms, self-efficacy, and temporal stability of intentions. Psychology of Sport and Exercise, 2010; 11: 71-79. https://doi.org/10.1016/j.psychsport.2009.05.010

30.Dishman R, Motl R, Saunders R, Felton G, Ward D, Dowda 
M, Pate R. Self- efficacy partially mediates the effect of a school-based physical-activity intervention among adolescent girls. Preventative Medicine, 2004; 38: 628-636. https://doi.org/10.1016/j.ypmed.2003.12.007

31.Gao A, Lochbaum M, Podlog L. Self-efficacy as a mediator of children's achievement motivation and in-class physical activity. Perceptual \& Motor Skills, 2011; 113: 969-981. https://doi.org/10.2466/06.11.25.PMS.113.6.969-981

32.Gao Z, Xiang P, Lochblaum M, Guan J. The impact of achievement goals on cardiorespiratory fitness: Does self-efficacy make a difference? Research Quarterly for Exercise and Sport, 2013; 84: 313-322. https://doi.org/10.1080/02701367.2013.814908

33.Aarnio M, Winter T, Peltonen J, Kunala M, Kaprio J. Stability of leisure-time physical activity during adolescence-A longitudinal study among 16-, 17- and 18- year-old Finnish youth. Scandinavian Journal of Medicine and Science in Sports, 2002; 12: 179-185. https://doi.org/10.1034/j.1600-0838.2002.00250.x

34.Standage M, Gillison FB, Ntoumanis N, Treasure DC. Predicting students' physical activity and health-related wellbeing: A prospective cross-domain investigation of motivation across school physical education and exercise settings. Journal of Sport and Exercise Psychology, 2012; 34(1):37-60. https://doi.org/10.1123/jsep.34.1.37

35.McDavid L, Cox AE, Amorose AJ. The relative roles of physical education teachers and parents in adolescents' leisure-time physical activity motivation and behavior. Psychology of Sport and Exercise, 2012;13:99-107.. https://doi.org/10.1016/j.psychsport.2011.10.003

36. Taylor I, Ntoumanis N, Standage M, Spray C. Motivational predictors of physical education students' effort, exercise intentions and leisure time physical activity: A multilevel linear growth analysis. Journal of Sport and Exercise Psychology, 2010; 32: 99-120. https://doi.org/10.1123/jsep.32.1.99

37.Cecchini-Estrada J, Mendez-Gimenez A. Motivational climate, $2 \times 2$ achievement goal orientation and dominance, selfregulationandphysicalactivityinpre-serviceteachereducation. European Physical Education Review, 2017; 23: 461- 479. https://doi.org/10.1177/1356336X16655779

38.Jagacinski CM. Women engineering students: Competence perceptions and achievement goals in the freshman engineering course. Sex roles, 2013; 69(11-12): 644- 657. https://doi.org/10.1007/s11199-013-0325-9

39. Gao Z, Lee AM, Kosma M, Solmon M. Understanding students' motivation in middle school physical education: examining the mediating role of self-efficacy on physical activity. International Journal of Sport Psychology, 2010; 41: 199- 215

40.Kane TD, Marks MA, Zaccaro SJ, Blair V. Self-efficacy, personal goals, and wrestlers' self-regulation. Journal of Sport \& Exercise Psychology, 1996; 18: 36-48. https://doi.org/10.1123/jsep.18.1.36

41. Guan J, McBride R, Xiang P. A comparison of the trichotomous and $2 * 2$ achievement goal models in high school physical education settings. Measurement in Physical Education and Exercise Science, 2007; 11: 109-129. https://doi.org/10.1080/10913670701294104

42.Pintrich P, Degroot E. Motivational and self-regulated learning components of classroom academic performance. Journal of Educational Psychology, 1990; 82: 33-40. https://doi.org/10.1037//0022-0663.82.1.33

43.Üredi I. Algllanan anne baba tutumlarının ilköğretim 8. sinıf ögrencilerinin öz-düzenleme stratejileri ve motivasyonel inançlarl üzerindeki etkisi [The effect of perceived parental attitudes on 8th graders' self-regulated learning strategies and motivational beliefs]. [PhD thesis]. Yıldız Teknik University; 2005.

44.Erturan-İlkerG,ArslanY,Demirhan G.Avalidity and reliability study of the motivated strategies for learning questionnaire. Educational Sciences: Theory \& Practice, 2014; 14(3): 9-13. https://doi.org/10.12738/estp.2014.3.1871

45.Sağlam M, Arıkan H, Savcı S, Inal-Ince D, Bosnak-Güçlü M, Karabulut E, Tokgözoğlu L. International physical activity questionnaire: Reliability and validity of the Turkish version. Perceptual and Motor Skills, 2010; 111: 278-284. https://doi.org/10.2466/06.08.PMS.111.4.278-284

46.Craig C, Marshall A, Sjostrom M, Bauman A, Booth $\mathrm{M}$, Ainsworth B, Oja P. International physical activity questionnaire: 12-country reliability and validity. Medical Science Sports Exercise, 2003; 35(8): 1381-1395. https://doi.org/10.1249/01.MSS.0000078924.61453.FB

47.Arbuckle J. AMOS (Version 17. 0). Chicago: Smallwaters Corporation. [Computer software]; 1999.

48.Hu L. Bentler PM. Cutoff criteria for fit indexes in covariance structure analysis. Conventional criteria versus new alternatives. Structural Equation Modeling: A Multidisciplinary Journal, 1999; 6(1): 1-55. https://doi.org/10.1080/10705519909540118

49. Tabachnick B, Fidell L. Using multivariate statistics. 5th ed. Boston: Pearson Education; 2007.

50.Byrne B. Structural equation modeling with basic AMOS basic concepts, applications, and programming. London: Lawrence Erlbaum Associates Publishers; 2001.

51.Elliot A. Integrating "classic" and "contemporary" approaches to achievement motivation: A hierarchical model of approach and avoidance achievement motivation. In: Pintrich P, Maehr M, editors. Advances in motivation and achievement Greenwich, CT: JAI Press; 1997; 10: P.143179.

52.Wang C, Liu W, Lochbaum M, Stevenson S. Sport ability beliefs, $2 \times 2$ achievement goals, and intrinsic motivation: The moderating role of perceived competence in sport and exercise. Research Quarterly for Exercise and Sport, 2009; 80(2): 303-312. https://doi.org/10.1080/02701367.2009.10599565

53.Li W, Shen B, Rukavina P, Sun H. Effect of perceived sport competence on intentions to exercise among adolescents: Mediating or Moderating. Journal of Sport Behavior, 2011; 34: 160-174.

54.Xiang P, McBride R, Bruene A, Liu Y. Achievement goal orientation patterns and fifth graders' motivation in a physical education running program. Pediatric Exercise Science, 2007; 19: 179-191. https://doi.org/10.1123/pes.19.2.179

55.Wolters C, YuS, PintrichP.Therelationbetweengoalorientations and students' motivational beliefs and self-regulated learning. Learning and Individual Differences, 1996; 8: 211-238. https://doi.org/10.1016/S1041-6080(96)90015-1

56.Cook D, Thompson W, Thomas K. The motivated strategies for learning questionnaire: Score validity among medicine residents. Medical Education, 2011; 45: 1230-1240. https://doi.org/10.1111/j.1365-2923.2011.04077.x

57.McCauley E, Blissmer B. Self-efficacy determinants and consequences of physical activity. Exercise and Sport Sciences Reviews, 2000; 28: 85-88. 


\section{Information about the authors:}

Erturan G.; (Corresponding author); http://orcid.org/0000-0002-1461-2679; gokce.erturan@gmail.com; Pamukkale University, Faculty of Sport Sciences; Kınıklı Campus, Denizli, Turkey.

McBride R.; http://orcid.org/0000-0002-7177-6741; mplelf4evr@gmail.com; Texas A\&M University, College of Education \& Human Development, Department of Health \& Kinesiology; Texas, USA.

Ağbuğa B.; http://orcid.org/0000-0002-4817-198X; bakboga@pau.edu.tr; Pamukkale University, Faculty of Sport Sciences; Kınıklı Campus, Denizli, Turkey.

Cite this article as:

Erturan G, McBride R, Agbuga B. Self-regulation and self-efficacy as mediators of achievement goals and leisure time physical activity: a proposed model. Pedagogy of physical culture and sports, 2020;24(1):12-20.

https://doi.org/10.15561/18189172.2020.0102

This is an Open Access article distributed under the terms of the Creative Commons Attribution License, which permits unrestricted use, distribution, and reproduction in any medium, provided the original work is properly cited (http://creativecommons.org/licenses/by/4.0/deed.en).

Received: 06.10.2019

Accepted: 08.11.2019; Published: 10.11.2019 